\title{
Declaração de conflito de interesse em apresentações e publicações científicas
}

\author{
Conflict of interest disclosure in public presentations \\ and scientific publications
}

Wallace Chamon, Luiz Alberto S. Melo Jr., Augusto Paranhos Jr.

\section{Introdução}

Uma das obrigações dos cientistas é a divulgação dos seus resultados. Ciência não divulgada causa mais danos que benefícios. Muitos pacientes aceitam a participação em ensaios clínicos com o desejo altruísta de promover o desenvolvimento da ciência e proporcionar tratamentos médicos mais eficazes; o pesquisador que não divulga seus resultados trai a confiança do paciente e da sociedade (representada pelos órgãos de avaliação da Ética em Pesquisa), que o permitiram realizar determinado projeto. Com os novos patamares atingidos pela produção científica brasileira vem o compromisso com a melhora de sua qualidade e a transparência na sua divulgação.

O "Conflito de Interesse" está presente quando existe uma ligação entre os interesses privados de um indivíduo, ou até mesmo de uma instituição representada por ele, e suas responsabilidades científicas. A "Declaração de Conflito de Interesse" faz parte da transparência científica, possibilitando ao leitor ou ouvinte avaliar se o comportamento do apresentador pode ter sido influenciado por esses interesses privados ${ }^{(1)}$. A caracterização de conflito de interesse não necessariamente significa que os envolvidos não mereçam credibilidade. Permite sim, que se tenha idéia dos personagens envolvidos no processo e suas motivações.

A integridade da pesquisa científica é fundamental e, muitas vezes, é conduzida por pesquisadores que têm algum ganho financeiro no processo. Assim como os resultados são importantíssimos para saúde da população, o ideal é que os estudos sejam conduzidos pelos melhores pesquisadores. Não seria salutar discriminar o pesquisador patrocinado pela indústria, mas é fundamental a clareza para com todos os envolvidos. Todos os personagens devem estar cientes de qualquer eventual benefício financeiro que alguém pode ter recebido durante o processo: elaboração da pesquisa, apresentação da pesquisa (esteja ou não envolvido na pesquisa em si) e assistência ao paciente. Conflitos de interesse podem existir em diferentes níveis, como na autoria ou apresentação da pesquisa, assim como na avaliação, revisão ou editoria dessa ${ }^{(2)}$.

Foi a partir da década de 80 que os periódicos biomédicos e alguns encontros científicos internacionais começaram a solicitar que os autores expusessem seus interesses financeiros sobre o assunto de seus manuscritos e apresentações ${ }^{(3)}$.

\section{Tipos de conflitos de interesse}

O conflito de interesse pode ser verdadeiro (factual) ou ser percebido como possível (potencial) ${ }^{(4)}$. Os conflitos de interesse podem ainda ser classificados como financeiro, pessoal, acadêmico, relacionado à afiliação institucional, político e religioso $^{(1-4)}$. Estes podem ser relacionados à alguma tecnologia utilizada na pesquisa ou na apresentação, assim como à alguma tecnologia concorrente a essa.

O conflito financeiro é o mais comum de ter a sua declaração exposta pelos autores ${ }^{(3)}$. Ele pode advir diretamente de salário, pagamento por consultoria ou verba de pesquisa ${ }^{(4)}$. Esse conflito de interesse também ocorre quando o indivíduo possui ações da empresa, ou está ligado à patente, royalties ou direitos autorais, bem como obtenção de benefícios sob a forma de honorários por palestras, inscrições em eventos científicos, passagens, estada ou presentes diversos ${ }^{(2)}$.

O conflito pessoal ocorre quando os autores do estudo são familiares, amigos, colegas, inimigos ou competidores ${ }^{(1)}$. Esse grau de amizade ou inimizade com os autores pode influenciar o julgamento do mérito científico do estudo por parte do revisor ou editor.

O conflito acadêmico se dá quando a paixão acadêmica exacerbada por um determinado tópico impede um julgamento acurado do mérito científico do manuscrito ${ }^{(1)}$. Se um revisor ou editor criou sua carreira científica baseado em uma teoria e recebe um manuscrito para avaliar cujo conteúdo contradiz essa teoria, sua capacidade de avaliar imparcialmente pode estar comprometida.

O conflito relacionado à afiliação institucional existe quando o processo de publicação pode ser facilitado ou dificultado a depender da instituição onde foi realizado o estudo ${ }^{(1)}$.

Os conflitos de ordem política e religiosa são mais raros, especialmente no meio oftalmológico.

\section{Relação temporal}

O benefício pode não estar diretamente relacionado temporalmente à ação do pesquisador. Esse intervalo de tempo pode ser interpretado como ausência de conflito de interesse, mas muitas vezes não é o caso. A janela de tempo usual é de 12 meses, mas existem periódicos que estendem este hiato até três anos ${ }^{(5)}$.

Uma revisão sistemática alemã de 2007, verificou que 13 das 31 revistas daquele país não tinham nenhuma referência sobre a 
caracterização de conflito de interesse ${ }^{(6)}$. Em publicação do mesmo ano no Brasil, de 20 revistas com a qualificação de nível A da CAPES, apenas $55 \%$ exigiam a caracterização de conflito de interesse, ou seja, há muito o que fazer ${ }^{(7)}$. Mais recentemente, uma pesquisa do periódico JAMA mostrou que de 256 periódicos médicos, $89 \%$ continham regras para caracterização de conflito de interesse e apenas $56 \%$ exigiam que o pesquisador assinasse um termo endossando-o. Quanto à caracterização de auxilio para viagens, somente $12 \%$ dos periódicos exigiam que se explicitasse esta forma de conflito ${ }^{(8)}$.

\section{Normas nacionais}

O Código de Ética Médica (17 de setembro de 2009) ${ }^{(9)}$, a Resolução 196/96 do Conselho Nacional de Saúde ${ }^{(10)}$, a Resolução da Diretoria Colegiada - RDC 96/2008 da Agência Nacional de Vigilância Sanitária ${ }^{(11)}$ e a Resolução 1.595/ 2000 do Conselho Federal de Medicina ${ }^{(12)}$ fazem menção aos conflitos de interesse.

O Código de Ética Médica, no seu artigo 104 menciona que "é vedado ao médico deixar de manter independência profissional e científica em relação a financiadores de pesquisa médica, satisfazendo interesse comercial ou obtendo vantagens pessoais" ${ }^{\prime(9)}$. O artigo 109 afirma que "é vedado ao médico deixar de zelar, quando docente ou autor de publicações científicas, pela veracidade, clareza e imparcialidade das informações apresentadas, bem como deixar de declarar relações com a indústria de medicamentos, órteses, próteses, equipamentos, implantes de qualquer natureza e outras que possam configurar conflitos de interesses, ainda que em potencial"'(9).

A Resolução 196/96 do Conselho Nacional de Saúde, na alínea (b) do item III.3, menciona que "a pesquisa em qualquer área do conhecimento, envolvendo seres humanos deverá assegurar a inexistência de conflito de interesses entre o pesquisador e os sujeitos da pesquisa ou patrocinador do projeto"(10).

A resolução RDC 96/2008 da Agência Nacional de Vigilância Sanitária, no parágrafo segundo do artigo 42, afirma que "os palestrantes de qualquer sessão científica que estabeleçam relações com laboratórios farmacêuticos ou tenham qualquer outro interesse financeiro ou comercial devem informar potencial conflito de interesses aos organizadores dos congressos, com a devida indicação na programação oficial do evento e no início de sua palestra, bem como, nos anais, quando estes existirem"(11).

Na resolução 1.595/2000 do Conselho Federal de Medicina, o artigo segundo determina "que os médicos, ao proferirem palestras ou escreverem artigos divulgando ou promovendo produtos farmacêuticos ou equipamentos para uso na medicina, declarem os agentes financeiros que patrocinam suas pesquisas e/ou apresentações, cabendo-lhes ainda indicar a metodologia empregada em suas pesquisas - quando for o caso - ou referir a literatura e bibliografia que serviram de base à apresentação, quando essa tiver por natureza a transmissão de conhecimento proveniente de fontes alheias. Parágrafo-Único - Os editores médicos de periódicos, os responsáveis pelos eventos científicos em que artigos, mensagens e matérias promocionais forem apresentados são co-responsáveis pelo cumprimento das formalidades prescritas no caput deste artigo"(12).

\section{Normas internacionais}

A Declaração de Helsinque, um dos documentos mais divulgados e seguidos pelos periódicos médicos em todo o mundo, contém princípios claros a serem seguidos por pesquisas médicas. Na sua última versão (2008), a Declaração de Helsinque expõe no princípio 30 que "fontes de fomento, afiliações institucionais e conflitos de interesse devem ser declarados na publicação"(13).

\section{Recomendações aos periódicos internacionais}

O Comitê Internacional de Editores de Periódicos Médicos (International Committe of Medical Journal Editors - ICMJE) recomenda que todos os indivíduos envolvidos no processo de publicação (autores, revisores e editores) exponham seus conflitos de interesse, sejam esses verdadeiros ou potenciais ${ }^{(2)}$. Para prevenir ambiguidades, caso não exista conflito de interesse, que se declare que não possui.

Os autores devem ainda mencionar o papel exercido pelo expositor do estudo, se participou no(a): delineamento do estudo; coleta, análise e interpretação dos dados; redação do manuscrito; decisão de submeter o manuscrito para publicação ${ }^{(2)}$.

Os editores deveriam evitar selecionar revisores com conflitos de interesse óbvios em relação ao manuscrito, como no caso de revisor que trabalha na mesma instituição que os autores. Os editores com poder de decisão final sobre o manuscrito não podem ter conflito de interesse em relação ao estudo ${ }^{(2)}$.

Outras orientações da literatura internacional, como o Manual de Estilo da Associação Médica Americana (American Medical Association Manual of Style) e o Conselho de Editores Científicos (Council of Science Editors - CSE) sugerem recomendações semelhantes às acima ${ }^{(3-4)}$.

\section{Conflitos de interesse e educação médica}

Outra fonte constante de questionamento é o envolvimento da indústria na educação médica. A atividade de educação pode ser patrocinada pela indústria ou por agências governamentais, a solução está mais uma vez na transparência. Quando há influencia da indústria, mesmo que seja somente na programação, isso deve ser caracterizado. Como a quantificação do vínculo é difícil, o ideal seria caracterizar entre duas possibilidades: aulas sem qualquer vínculo com a indústria no que tange ao conteúdo, programação e escolha de palestrantes, e aulas em que qualquer vínculo seja caracterizado. Isso possibilita ao público assistir a um evento sabendo dos interesses envolvidos. Esta caracterização valeria para organização de eventos de uma forma geral, mas não se aplicaria ao palestrante individualmente. Este tem que caracterizar seu conflito de interesse a despeito da aula ou módulo nada ter a ver com a indústria.

\section{Responsabilidade da declaração de conflitos de interesse}

A quem cabe a responsabilidade da caracterização do conflito de interesse? Em algumas revistas é o primeiro autor, em outras, o 
autor de correspondência. No entanto todos os autores e apresentadores devem ser questionados. Não existe a possibilidade de uma fiscalização efetiva quanto à integridade da declaração de conflito, mas a declaração falsa pode ser considerada como fraude e os responsáveis responderem legalmente pela infração. Casos famosos como o do ex-chefe do FDA que em 2006 foi multado em U\$ 90.000,00 e condenado a três anos de suspensão condicional e a 50 horas de serviços públicos por não ter caracterizado conflito de interesse dele e de sua mulher podem mudar o cenário $^{(14)}$. O caminho futuro possivelmente passará pela declaração compulsória do financiamento pela indústria de pesquisas, de passagens para médicos e pesquisadores, etc. para que os periódicos possam acessar em bancos de dados e fiscalizar a lisura das informações passadas pelo pesquisador.

\section{Os Arquivos Brasileiros de Oftalmologia}

Atualmente, os Arquivos Brasileiros de Oftalmologia solicita que os autores declarem os conflitos de interesse assim como a participação de patrocinadores no manuscrito em formulários separados que são encaminhados no momento do envio inicial do manuscrito. Até esse momento, os revisores e editores não são questionados sobre conflito de interesse na avaliação dos manuscritos.

Cabe à comunidade oftalmológica brasileira colocar rapidamente em prática métodos transparentes de exposição dos conflitos de interesse em todas apresentações científicas e didáticas, sejam elas escritas ou orais.

\section{REFERÊNCIAS}

1. World Association of Medical Editors. Conflict of interest in peer-reviewed medical journals: a policy statement of the World Association of Medical Editors (WAME). J Child Neurol. 2009;24(10):1321-3.

2. International Committee of Medical Journal Editors. Uniform Requirements for
Manuscripts Submitted to Biomedical Journals: Ethical Considerations in the Conduct and Reporting of Research: Conflicts of Interest. [Internet]. 2009 [cited 2010 Apr 15], Available from: http://www.icmje.org/ethical_4conflicts.html.

3. American Medical Association. Conflict of Interest Policy And Statement on Disclosure of Affiliations [Internet]. 1999 [cited 2010 Apr, 15]; Available from: http://www.ama-assn.org/ama1/pub/upload/mm/37/coi-policy.doc

4. Council of Science Editors. Guidance for Journals Developing or Revising Policies on Conflict of Interest, Disclosure, or Competing Financial Interests [Internet]; 2005 [cited 2010 Apr 15]; Available from: http://www.councilscienceeditors.org/events/ retreat_paper_2005-02.pdf.

5. Klein D, Glick I. Conflict of interest, journal review, and publication policy. Neuropsychopharmacology. 2008;33(13):3023-6.

6. Schneider N, Lingner H, Schwartz F. Disclosing conflicts of interest in German publications concerning health services research. BMC Health Serv Res. 2007;7:78.

7. Tavares-Neto J, Azevedo ES. Destaques éticos nos periódicos nacionais das áreas médicas. Rev Assoc Med Bras. 2009;55(4):400-4.

8. Blum JA, Freeman K, Dart RC, Cooper RJ. Requirements and definitions in conflict of interest policies of medical journals. JAMA. 2009;302(20):2230-4

9. Conselho Federal de Medicina. Resolução 1931/2009. Aprova código de ética médica [Internet]. Diário Oficial da União (DOU), 24 de setembro de 2009; seção I, p.90]. [citado 2010 Abr 15]. Disponível em: www.amib.org.br/pdf/RESOLUÇÃO_CFM_1931.pdf.

10. Brasil. Ministério da Saúde. Conselho Nacional de Saúde. Resolução 196 de 10 de outubro de 1996. Diretrizes e normas regulamentadoras de pesquisas envolvendo seres humanos [Internet]. Brasília: Ministério da Saúde; 1996. [citado 2010 Abr 15] Disponível em: http://www.datasus.gov.br/conselho/resol96/ RES19696.htm.

11. Agência Nacional de Vigilância Sanitária. Resolução da Diretoria Colegiada (RDC) $\mathrm{n}^{\circ} 96$ de 17 de dezembro de 2008. Dispõe sobre a propaganda, publicidade, informação e outras práticas cujo objetivo seja a divulgação ou promoção comercial de medicamentos [Internet]. Brasília: ANVISA; 2008. [citado 2010 Abr 15]. Disponível em: www.anvisa.gov.br/propaganda/rdc/rdc_96_2008_consolidada.pdf.

12. Conselho Federal de Medicina. Resolução CFM n. 1595/2000. Disciplinar a propaganda de equipamentos e produtos farmacêuticos junto à categoria médica, além de salientar a importância de que possíveis conflitos de interesse no relacionamento entre médicos e a indústria farmacêutica sejam explicitados, sempre que necessário. Brasília: CFM; 2000. [citado 2010 Abr 15]. Disponível em: http:// www.portalmedico.org.br/resolucoes/cfm/2000/1595_2000.htm.

13. World Medical Association Declaration of Helsinki. Ethical Principles for Medical Research Involving Human Subjects [Internet]. In: World Medical Association General Assembly, Seoul, oct. 2008. p.2-4.[cited 2010 Apr 15]. Available from: http://www.wma.net/en/30publications/10policies/b3/17c.pdf

14. Tanne JH. Former FDA commissioner is fined 90,000 dollars for failing to disclose conflicts of interest. BMJ. 2007;334(7592):492.

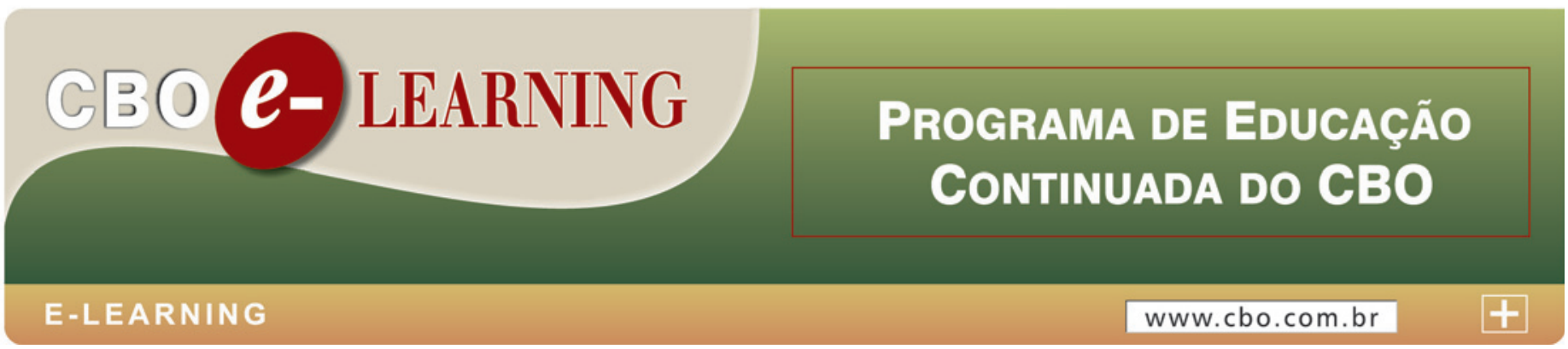

